\title{
Biogenic Isoprene and Its Impact on Human Health in Dependence on Meteorological Conditions
}

\author{
_-Special Issue “Air Pollution”
}

\author{
Sascha Henninger \\ Department of Physical Geography, University of Kaiserslautern, Kaiserslautern, Germany. \\ Email: sascha.henninger@ru.uni-kl.de
}

Received June $12^{\text {th }}, 2012$; revised July $11^{\text {th }}, 2012$; accepted August $6^{\text {th }}, 2012$

\begin{abstract}
Urban green areas have an important implication on the local climate. A cross-linkage of many small green spaces could result in decreasing the effect of the urban heat island, but also increase people's thermal comfort. By the way, urban green areas could also induce a positive effect on the local urban air quality. But attention has to be paid to the assortment of the tree species. More or less all tree species are emitting biogenic volatile organic compounds in different concentration. These serve as precursors for the formation of ozone near the ground. So near surface ozone has the ability to react with different particulate matters and could become toxic, due to oxidation or nitrification. This causes inflammations and inspired allergens may increase the risk of a respiratory disease. Therefore, an analysis and assessment of the urban green area air quality could help to make a statement about the recreational effect of these areas in dependence of the leading vegetation and for that matter for the exposure to ozone. By the help of these the results can be used as a guidance of urban planning taking into account the influence of biogenic emission as a function of actual weather conditions.
\end{abstract}

Keywords: Biogenic Isoprene; Ozone; Urban Green; Air Quality

\section{Introduction}

From the viewpoint of urban ecology, especially the urban climatology, urban green areas have an important implication on the local climate. The aim of the applied, planning-oriented urban climatology is to create a synergy effect between the positive recreational use of these green spaces and its positive consequences on local climate and air quality [1].

But attention has to be paid to the assortment of the tree species: Some trees have the ability to affect the local air quality negatively. More or less all tree species emit biogenic volatile organic compounds (BVOCs) in different concentration (e.g. isoprene and terpenes) [2]. These serve as precursors for the formation of ozone near the ground. Especially within urban green areas, which act as a resort for many people, wrong tree populations are contraindicated, because this could lead to a significant exposure to noxious ozone. When many people visit an urban green space (clear and calm weather conditions with hot summery temperatures, low wind speed and a high solar radiation) the emission of BVOCs is highest, and ozone concentration is accordingly high as well [3]. Especially within urban green areas it is important to take care of reducing the potential volatile organic compound sources to minimize the formation of ozone, because this could lead to negative impacts on human health. So near surface ozone has the ability to react with particulate matters (e.g. soot, polycyclic aromatic hydrocarbons, pollen) to form free radicals of oxygen. As a consequence, soot or pollen could become toxic, due to oxidation or nitrification. This causes inflammations and inspired allergens could increase the risk of a respiratory disease [4]. Therefore, an analysis and assessment of the urban green area air quality could help to make a statement about the recreational effect of these areas in dependence of the leading vegetation and for that matter for the exposure to ozone. In cooperation with emergency medical services a first step could be made to draw a conclusion for the relation between clear and calm weather conditions with a high formation-potential of near surface ozone and incidences of respiratory diseases. These could be indicated by the insets of the local ambulance services. By the help of these the results can be used as a guidance of urban planning taking account of the influence of biogenic emission as a function of actual weather conditions $[5,6]$. 


\section{Near Surface Ozone and Biogenic Isoprene}

Carbon monoxide (CO), nitrogen monoxide (NO) and non-methane hydrocarbons (NMHC's) are primary air pollutants. But there are also the secondary pollutants (e. g. nitrogen dioxide $\left(\mathrm{NO}_{2}\right)$ and ozone), which are formed by the emissions of primary trace elements by diverse chemical reactions. Mainly, the corresponding precursors of $\mathrm{O}_{3}$ are $\mathrm{NO}$ and the anthropogenic NMHCs. Indeed, it should not be neglected that there are also some biogenic emissions, which have the ability to react with anthropogenic trace elements and form secondary air quality indicators. One of these is the biogenic hydrocarbon isoprene. It could form ozone due to its great capacity of reaction. Actually, in comparison to anthropogenic hydrocarbons, isoprene could already start a formation with $\mathrm{O}_{3}$ less concentrated [7]. That is why isoprene is one of the precursors, which has to be taken seriously. The rate of emission is dependent on the meteorological conditions (air temperature and solar radiation) and how these affect the stock of vegetation (leaf temperature). The emission of isoprene is determined by the height of the air temperature and the intensity of the photosynthetic active radiation (PAR). This relation can be reconstructed by Equation (1) [8]:

$$
\mathrm{E}_{\text {isoprene }}=\mathrm{Es}_{\text {isoprene }} \mathrm{HCLT}
$$

by $\mathrm{E}=$ rate of emission $\left[\mu \mathrm{g} \cdot \mathrm{g}(\text { dry weight })^{-1} \cdot \mathrm{h}^{-1}\right]$;

Es $=$ standardized rate of emission $\left[\mu \mathrm{g} \cdot \mathrm{g}(\text { dry weight })^{-1} \cdot \mathrm{h}^{-1}\right]$;

$\mathrm{H}=$ correction term for air humidity;

$\mathrm{C}=$ correction term for atmospheric $\mathrm{CO}_{2}$ concentration;

$\mathrm{L}=$ correction term for intensity of the solar radiation;

$\mathrm{T}=$ correction term for leaf temperature.

According to this, clear and calm weather conditions with a high solar radiation and high air temperature are best qualified for leading to a high emission rate of isoprene from the plants' leaves. Even for the days with expected high concentration of ozone the amount of additional biogenic hydrocarbon, such as isoprene, may contribute to further formation of $\mathrm{O}_{3}$, too. This occurs especially within areas like urban parks, where at first sight high ozone levels are not estimated.

Down to the present day there is a number of publications which deal with the analysis of urban trees and their potential of forming near surface ozone along roadsides as well as within urban green areas [5,9-11]. Since Taha [12] the terms of "low-" and "high-emitter"-plants are used. The consideration of these low- or high-emitting trees species may have a sustainable impact on the emission of biogenic hydrocarbons and thus on the formation of ozone.

\section{Ozone and Aerosol Particles}

The possible heterogeneous reactions of ozone with dif- ferent aerosol particles (e.g. soot, pollen, polycyclic aromatic hydrocarbons) are of special interest especially to urban air quality. So-called reactive oxygen species (ROS) play a key role in the chemical transformation and adverse health effects $[4,13,14]$. These are closely coupled by radical reactions and cyclic transformation to become toxic or allergenic air-particulate matters. The different types of reactive oxygen species can proceed through various interfaces, not at least in the human respiratory tract $[4,15]$. In the meantime a lot of heterogeneous reactions of $\mathrm{O}_{3}$ with aerosol particles are analyzed. Polycyclic aromatic hydrocarbons (PAHs) are one prominent group of organic aerosol components that could readily react with ozone, to the disadvantage of human health. PAHs are an integral component of soot and other carbonaceous combustion aerosol particles. These have the ability to penetrate deep into humans lungs. Related with $\mathrm{O}_{3}$ a chemical reaction can change its toxicity. But ozone could also promote the nitration of protein molecules containing biological aerosol particles, such as pollen and fungal spores respectively $[16,17]$. This reaction is able to enhance the allergenic potential of proteins.

As a consequence, due to oxidation or nitrification processes, air-borne soot or pollen could become toxic. This causes inflammations and inspired allergens may increase the risk of a respiratory disease especially for the characteristic risk groups of asthmatics, allergic persons and small children.

\section{Investigation Area}

The so-called "Volkspark" in the city of Kaiserslautern, Germany $\left(49^{\circ} 14^{\prime} \mathrm{N}, 7^{\circ} 53^{\prime} \mathrm{E}\right)$, was chosen to prove the measuring methodology. This urban green area is one of the most frequented recreational areas in Kaiserslautern and is used for leisure by the direct residents, but also by people from the outskirts. Many events act as attraction, but there are also many leisure-time possibilities within the area. With a size of approximately nine hectares the "Volkspark" is coevally the biggest urban green space in the city. The park area is bounded by four-lane streets in the west and south. The green space can be divided into several types of land usage: lakes/ponds (4\%), lawns $(62 \%)$, flowerbeds $(4 \%)$, bushes $(11 \%)$, forest area $(3 \%)$, diverse open spaces $(1 \%)$ and $11 \%$ sealed areas. In reference to [18] generally all urban green spaces with more or less the same typical and characteristic park vegetation and a comparable proportion display that the question of reproducibility and transferability to other urban green areas would be answered positively and could also be treated as a guidance for other urban park areas.

\section{Measuring Methodology}

The air quality measurements as well as the climatological ones were taken by a mobile laboratory. This meth- 
odology allows measuring the air quality and meteorology at one special type of land use, but also at different locations if necessary, which is a great advantage in comparison to stationary measurements [19]. The aim of this measuring methodology was to determine the diurnal course of the different air pollutants concentration in relation to the meteorological conditions within the urban green area. Thus it should be possible to prove the daily air quality and how it was influenced respectively dependent by different external influencing factors. Beside ozone carbon monoxide, carbon dioxide, nitrogen monoxide, nitrogen dioxide and aromatic hydrocarbons (benzene, toluene, ethylbenzol, m-, o-, p-xylene) were measured. The air quality indicators were determined by a suction device of the mobile laboratory at $4 \mathrm{~m}$ above ground level. Additionally air temperature, air humidity, global and solar radiation were measured in 2 and $4 \mathrm{~m}$ a. g. 1. respectively, wind speed and direction were determined in $10 \mathrm{~m} \mathrm{a}$ g. 1 by a 3-D sonic anemometer. Though it is possible to display the results as a time line or in dependence of wind speed, it is more favorable in dependence of the wind direction. This enables an exact temporal allocation to the potential sources of emission of the specific air pollutants within and outside the urban park area. In addition to the determined 1min- and 15-min-average mean values for calculating the data in different time intervals, also integrated 1-h-average mean values of the aromatic hydrocarbons were detected.

The analysis of the biogenic emissions was limited to isoprene, because the air quality of the investigation area should be exemplarily assessed by the ozone. So using this natural hydrocarbon as its precursor was the logical consequence. The determination of the isoprene was very complicated and the measuring methodology had to be adapted to the requirements of this investigation. Generally, the analysis of biogenic hydrocarbons ensued by turning a cuvette directly on the branches of the trees [20]. For this investigation first of all a mapping of the area s vegetation was done. In the process all spaces with potential isoprene emission sources species were particularly marked. Subsequently, a mobile measuring transect across the "Volkspark" was constructed. Measurements were taken every 30 minutes and the air sampling was done in $1.50 \mathrm{~m}$ a. g. 1. with air-sampling tubes. The sampled gas was pumped through the tube filled with an appropriate reagent that absorbs the wanted biogenic hydrocarbon in the air to form a complex. Then this complex is made to react with other chemicals to form a second colored complex. The intensity and the concentration could be read out some minutes later on a scale respectively. With the aid of this semi-mobile measuring methodology isoprene could be detected directly and analyzed as well [5].

\section{Perceptions}

\subsection{Theoretical Estimation of the Biogenic Isoprene Emission Rate}

Immediately after the mapping of the vegetation it was possible to calculate the theoretical rate of isoprene emission in dependence of the occurring species, considering an optimum of meteorological conditions (Figure 1). Indeed, it must be mentioned, that this estimation of biogenic emissions is afflicted with some uncertainties (e.g. phytomass, single or group trees, tanning). Nevertheless, the estimation should not be neglected, because it creates an image of the pattern of emission that is very helpful for the ongoing analysis of the air quality situation within the investigation area.

The mapping resulted in a typical park vegetation with a heterogeneous structure of single trees, groups of trees and small forest areas. Altogether within the "Volkspark" there are 701 individuals, combined with diverse species, whereas at least Aceraceae, Betulaceae, Fagaceae, Malvaceae and Platanaceae placed $79 \%$ of the total stock. For measuring isoprene this was an advantage, because the species of plane (Platanaceae), beech trees (Fagaceae) and lime tress (Malvaceae) are considered as potential emitters of isoprene.

In dependence of the meteorological conditions these tree locations could be assumed as biogenic isoprene sources. An assembly of the dominant groves is shown in Table 1. Additionally the specific rates of isoprene emissions are also offered. The highest rate of emission could be expected for planes (Platanus acerifolia) and oaks (Quercus robur) and had to be identified as "high-emitter"-plants. Likewise the lime (Tilia concordata) and the birch (Betula pendula) must be counted as "high-emitters", too. Attention should be paid to the fact that at least plane and oak trees set $47 \%$ of all species within the investigation area. The other individuals revealed values less than $2 \mu \mathrm{g} \cdot \mathrm{g}(\text { dry weight })^{-1} \cdot \mathrm{h}^{-1}$ and must be referred as "low-emitter"-plants (Figure 1).

Now it is possible to make a calculation of the total emission. The specific emission rate of isoprene $[\mu \mathrm{g} \cdot \mathrm{g}(\mathrm{dry}$ weight $)^{-1} \cdot h^{-1}$ ] must be multiplied with the average biomass $[\mathrm{g}]$ of the respective species and the number of appropriate individuals. In reference to Benjamin \& Winer [11], but above all to Strassburger [21], the average biomass was assumed a dry weight of leaves of $15 \mathrm{~kg}$ per tree. Exemplarily, it could be calculated that solely the most important "high-emitter"-plants of the investigation area, shown in Table 1, offer a theoretical isoprene emission rate of $6.8 \mathrm{~g} \cdot \mathrm{h}^{-1}$. All in all this resulted in an biogenic isoprene emission rate of $8.8 \mathrm{~g} \cdot \mathrm{h}^{-1}$ for all mapped tree species of the vegetation stock of the "Volkspark" during the day time hours, in dependence of optimal meteorological conditions (Table 1). 


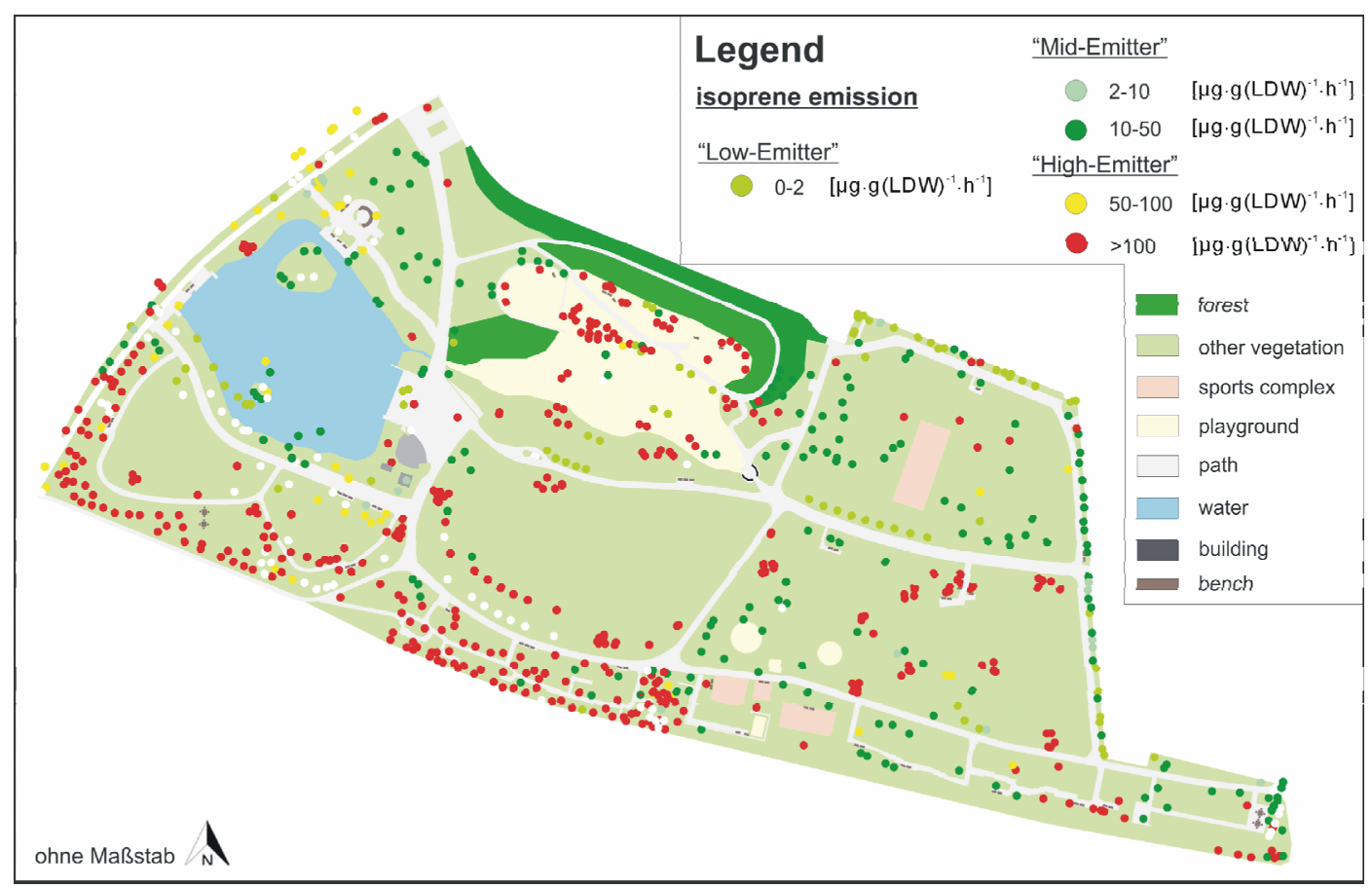

Figure 1. Mapping of the different theoretical isoprene sources in dependence of the different tree species within the "Volkspark", Kaiserslautern, Germany.

Table 1. Assembly of the dominant groves within the "Volkspark" and their specific rates of isoprene emission plus the rate of emission per tree considering an average leaf mass of $15 \mathrm{~kg}$ per individual.

\begin{tabular}{ccccc}
\hline Scientific name & $\begin{array}{c}\text { Specific rate of isoprene emission } \\
{\left[\mu \mathrm{g} \cdot \mathrm{g}(\mathrm{dry} \text { weight })^{-1} \cdot \mathrm{h}^{-1}\right]}\end{array}$ & $\begin{array}{c}\text { Rate of isoprene emission per } \\
\text { individual }(15 \mathrm{~kg})\left[\mu \mathrm{g} \cdot \mathrm{h}^{-1}\right]\end{array}$ & $\begin{array}{c}\text { Number of } \\
\text { individuals }\end{array}$ & $\begin{array}{c}\text { Rate of emission per species } \\
{\left[\mathrm{mg} \cdot \mathrm{h}^{-1}\right]}\end{array}$ \\
\hline Acer campestre & 8 & 120 & 25 & 3 \\
Platanus acerifolia & 883 & 13,245 & 22 & 291.39 \\
Quercus robur & 1405 & 21,075 & 310 & 6533.25 \\
Tilia concordata & 26 & 390 & 72 & 28.08 \\
Betula pendula & 25 & 375 & 45 & 16.88 \\
Amount & & & 474 & 6872.6 \\
Total park area & & & 701 & 8874.05 \\
\hline
\end{tabular}

By calculating the so-called maximum incremental reactivation of isoprene $\left(\mathrm{MIR}_{\mathrm{i}}\right)$, it is possible to analyze which amount of ozone could be formatted theoretically by the current emission of isoprene. So the incremental reactivation of isoprene is 9.1 [22]. Taking account of the $\mathrm{MIR}_{\mathrm{i}}$, the mentioned total amount of isoprene emission within the investigation area (Table 1) and the assumption of clear and calm weather conditions, the biogenic isoprene may cause a theoretical $\mathrm{O}_{3}$ concentration of 90.4 $\mu \mathrm{g} \cdot \mathrm{m}^{-3} \cdot \mathrm{h}^{-1}$.

\subsection{Biogenic and Anthropogenic Hydrocarbons within the "Volkspark"}

The initial results are attributed to a measuring period revealing excellent meteorological situation. Above all the solar radiation with a maximum of $979 \mathrm{~W} \cdot \mathrm{m}^{-2}$, a maximum air temperature of $36.9^{\circ} \mathrm{C}$ and an average wind speed of less than $1 \mathrm{~m} \cdot \mathrm{s}^{-1}$ for all days were very good conditions to form near surface ozone within the green area. Due to the minor atmospheric exchange a longrange transport from outside the investigation area into it could be excluded.

As expected there was a temperature inversion above the park area in the early morning hours. Noticeably, the concentration of isoprene was likewise high in the morning hours. This could be explained, because isoprene's source could be anthropogenic as well as biogenic. So at this time the hydrocarbon was mainly caused by traffic. 
Approximately $90 \%$ of the total reactivity related to the amount of both hydrocarbons omit to the isoprene source traffic. So it could be concluded that the rate of the anthropogenic isoprene reacted and urged the formation of near surface ozone. Indeed, the solar radiation in the morning hours was not strong enough to initiate an essential photochemical process to form ozone in high concentration.

Between noon and the afternoon hours there was no significant influence by traffic. At this time of the day air temperature as well as solar radiation reached their maximum. So, with a slightly temporal offset, the near surface $\mathrm{O}_{3}$ obtained its daily maximum around 5 p.m. as well. Owing an afternoon wind speed of less than $1 \mathrm{~m} \cdot \mathrm{s}^{-1}$ and a wind direction from east a long-range transport as well as a transport from the nearby vicinity of the investigation area could be neglected. By implication this means that the existing and measured $\mathrm{O}_{3}$ could only be formed within the urban park area. Analyzing the diurnal concentration of isoprene, this assumption was verified. A very good parallelism between the development of the increasing ozone concentration and isoprene was visible. Whereas the concentration of the traffic-induced pollutants was regressive at this time of the day, it could be postulated that a majority of the isoprene was not induced from an anthropogenic source. The alleged optimal meteorological conditions lead to an increasing rate of emission from the vegetation. So biogenic isoprene was able to be the current precursor to form near surface ozone. This could be verified by the total reactivity of the hydrocarbons. In dependence of the total amount of all measured ones isoprene offered a rate of $30 \%$.

During the early evening hours and due to the presence of $\mathrm{NO}$ the near surface $\mathrm{O}_{3}$ was destroyed and its concentration was decreasing plainly within the investigation area. The evening hours offered almost completely the anthropogenic isoprene caused by traffic. Lower air temperature and missing solar radiation encouraged a slowdown of the isoprene emission. Comparable to the morning hours the rate of the biogenic isoprene was solely $4 \%$.

Calculating the ozone output in dependence of the measuring period the detected anthropogenic and biogenic hydrocarbons displayed a remarkable authoritative statement, which could not be expected at the beginning of the measurements, but in conjunction with the nearly perfect environmental conditions it is at least no surprise. For the afternoon hours it was verifiable that $7 \%$ of the near surface ozone could be ascribed to the biogenic precursor isoprene. These results could be aligned with [21], who located a rate of $6 \%$ biogenic isoprene within the "Grugapark" in Essen, Germany.

In dependence of the meteorological conditions, especially in respect of the atmospheric stability of the boundary layer, places with "high-emitter"-plants reveal the highest concentration could be determined. As it is shown in Figure 2, these are unfortunately congruent with two red-colored areas, where it could be expected to

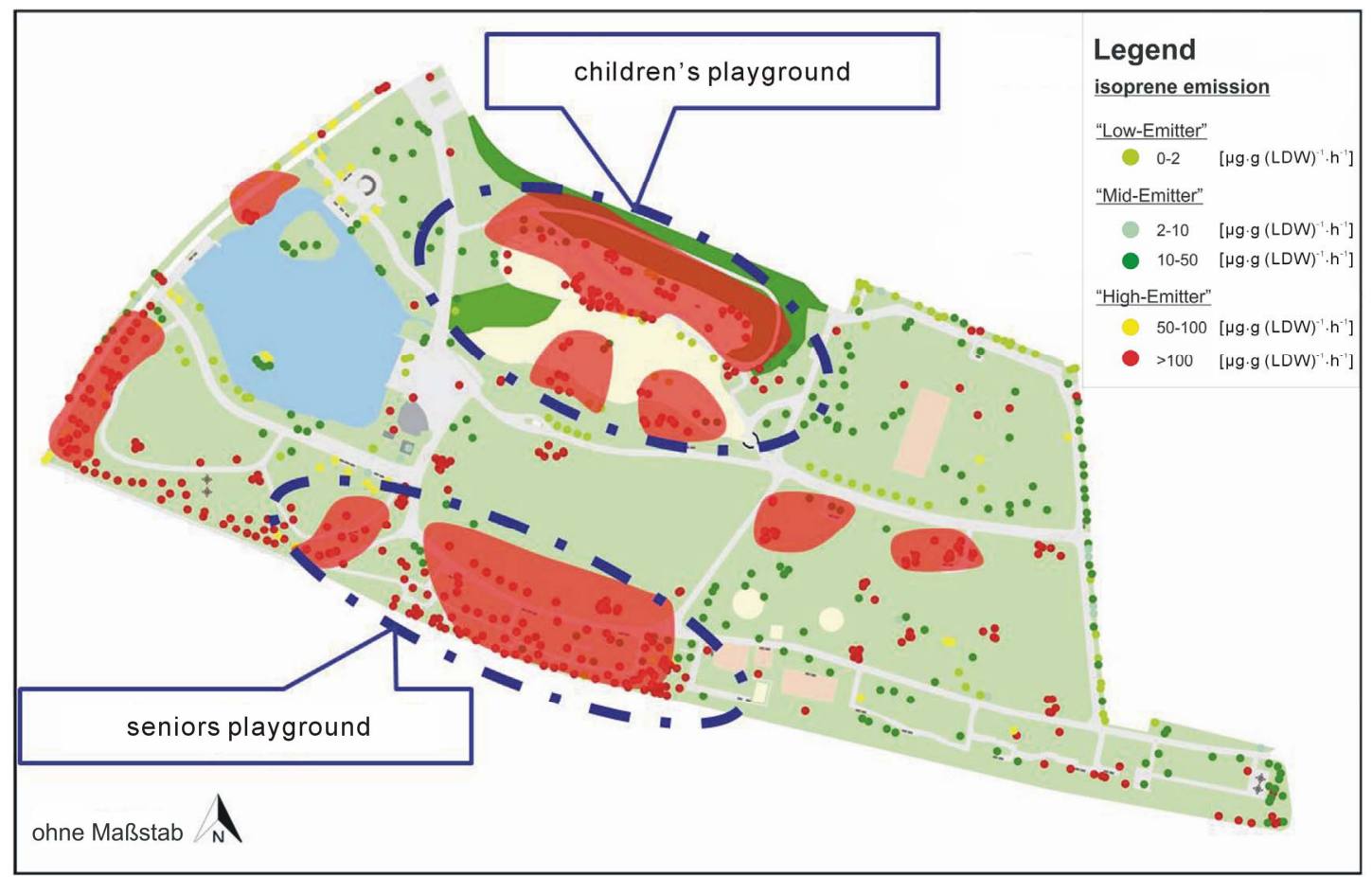

Figure 2. Mapping of places with the highest $\mathrm{O}_{3}$-concentration within the investigation area "Volkspark", Kaiserslautern, Germany. 
find the highest frequency of people belonging to the risk group children (children's playground) and elderly people (seniors playground).

\section{Respiratory Diseases}

Following the question whether the high ozone concentration within urban green spaces may affect the visitors health a cooperation with the German Red Cross (DRK) should help to answer the set of problems. The emergency medical service of the DRK is responsible for the coordination of all emergency insets within the urban area of Kaiserslautern. All different disease patterns were documented with all kinds of information, like the site of operation, the operating time and the description of the inset. So it is possible to create a map of the diverse emergency insets over the whole urban area. Hence, a first step was done to draw a conclusion for the relation between clear and calm weather conditions with a high formation-potential of near surface ozone and incidences of respiratory diseases. These could be indicated by the insets of the local ambulance services. As it is shown in Figure 3(a), of all different surgical, internal and pediatric emergencies $(n=11,163)$ in the city of Kaiserslautern, $11 \%(\mathrm{n}=1228)$ were respiratory diseases. A consultation with specialized medics for respiratory diseases $34 \%(n=$ 418) of these could be attributed to diseases (breathing difficulties, anaphylaxis and asthma attacks), which could be caused by inspired allergens (Figure 3(b)).

Analyzing the appearance of respiratory emergencies it could be shown, that there are more numerous in summer than in winter. Indeed, it was absolutely remarkable, that another $42 \%(n=176)$ of these emergencies could be located along the investigation area for the summer months between June and September, which could be located by the operating sites of the ambulances at the five entrances of the urban park area (Figure 3(c)).

\section{Conclusion}

It is indisputable that urban green spaces have a positive impact on their nearby vicinity, but also for the residents. Though it does not matter, if it is a positive effect on the local climate or for recreational values. Even in midsummer people aspire enhanced within urban green spaces to use restful utilization of these. Nevertheless, an awkward, particularly, also thoughtless planting could lead to an accumulation of air pollutants. From the applied climatology's point of view it is necessary to think about planning new vegetation within urban parks. In comparison to a climatic adjusted construction all over the urban area, likewise for new plantings throughout the planning phase the predominantly planted species must be considered in the right way. The analysis of the air pollution situation within the "Volkspark" in the city of Kaiserslautern inevitably revealed that during clear and calm weather conditions biogenic precursors could be emitted by diverse plants. Less atmospheric exchange, high air temperature and solar radiation arrange it so that near surface ozone is formed. Due to the fact that this air quality indicator could be diluted or dispatched the accumulation of it leads to high concentration which obviously exceed the limiting values. Not least this is ascribed to a vegetation stock with a rate of more than $70 \%$ so-called "high-emitter"-plants. So it could be calculated that a wrong proportion of species which emit higher or

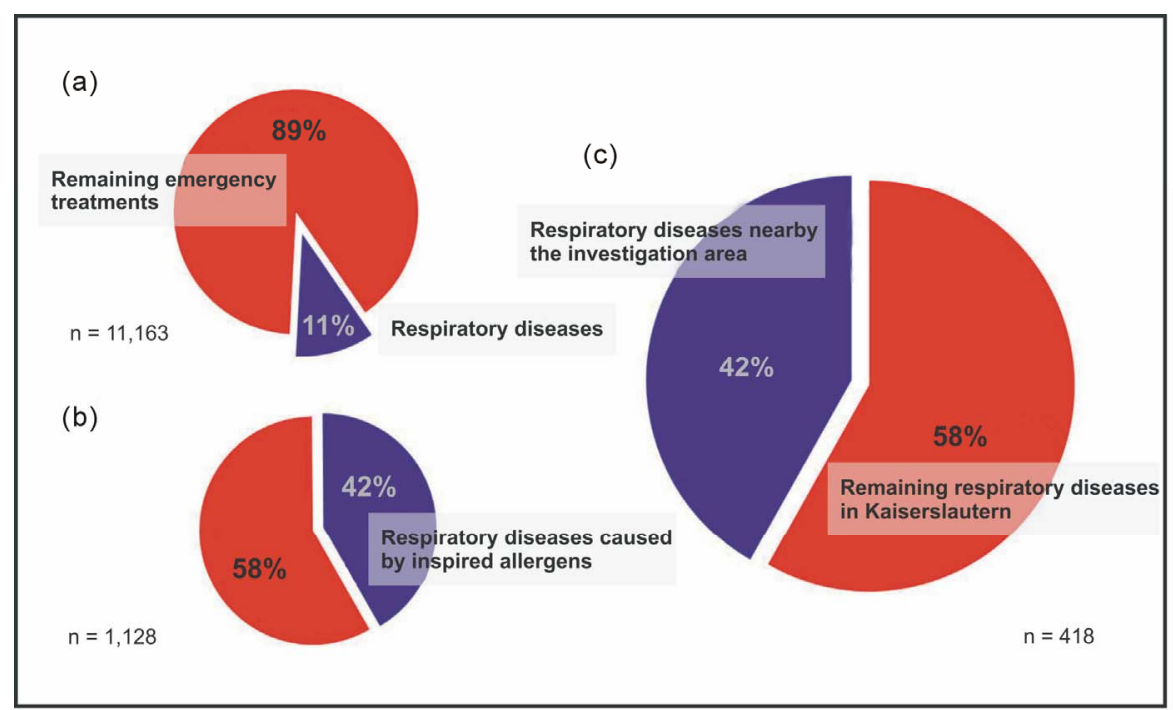

Figure 3. (a) Share of respiratory diseases (blue field) in comparison to the remaining emergency treatments; (b) Share of respiratory diseases, which could be caused by inspired allergens (blue field); (c) Share of respiratory diseases (blue field), which could be caused by inspired allergens with emergency insets along the investigation area "Volkspark", Kaiserslautern, Germany. 
lower rates of biogenic hydrocarbons and the size of the green area lead to a location-based formation of near surface ozone by $5 \%$ to $10 \%$ caused by e.g. biogenic isoprene. Finally, it ends in a negative assessment of the recreational value of such an area in relation to the benefits which an urban green area should rather have. However, and this could also be proved, it is possible to react on this. Planning oriented recommendations for action could be given for optimizing the air quality situation. Ultimately, it is frequently only the lack of knowledge that diverse species of the current vegetation stock of an urban park lead verifiably to an increase of the local near surface ozone concentration.

\section{REFERENCES}

[1] C. Ren, E. Ng and L. Katschner, "Urban Climatic Map Studies: A Review," International Journal of Climatology, Vol. 31, No. 15, 2011, pp. 2213-2233. doi:10.1002/joc. 2237

[2] T. Sharkey, A. Wiberley and A. Donhoue, "Isoprene Emission from Plants. Why and How," Annals of Botany, Vol. 101, No. 1, 2008, pp. 5-18. doi:10.1093/aob/mcm240

[3] F. Pacifico, S. P. Harrison, C. D. Jones and S. Sitch, "Isoprene Emission and Climate," Atmospheric Environment, Vol. 43, No. 39, 2009, pp. 6121-6136. doi:10.1016/j.atmosenv.2009.09.002

[4] M. Shiraiwa, Y. Sosedova, A. Rouviere, H. Yang, Y. Zhang, J. P. D. Abbat, M. Ackermann and U. Pöschl, "The Role of Long-Lived Reactive Oxygen Intermediates in the Reaction of Ozone with Aerosol Particles," Nature Chemistry, Vol. 3, 2011, pp. 291-295. doi:10.1038/nchem.988

[5] S. Henninger, "Urban Green Areas: Lots of Benefits, but some Drawbacks," Proceedings REAL CORP: Change for stability: Lifecycles of Cities and Regions, Essen, 2011, pp. 1069-1077.

[6] S. Henninger, "Urban Green and near Surface Ozone," Proceedings Regional Geography: Climatology—Instituto Geografico Militar, 2011, pp. 78-87.

[7] W. P. L. Carter, "Development of Ozone Reactivity Scales for Volatile Organic Compounds," Journal of the Air and Waste Management Association, Vol. 44, 1994, pp. 881-899.

[8] A. B. Guenther, R. L. Monson and R. Fall, "Isoprene and Monoterpene Emission Rate Variability: Observation with Eucalyptus and Emission Rage Algorithm Development," Journal of Geophysical Research, Vol. 96, No. D6, 1991, pp. 10799-10808. doi:10.1029/91JD00960

[9] W. Kuttler, "Climate Change in Urban Areas. Part 2, Measures," Environmental Science Europe, Vol. 23, 2011, p. 21. doi:10.1186/2190-4715-23-21
[10] P. J. Young, A. Arneth, G. Schurgers, G. Zeng and J. A. Pyle, "The $\mathrm{CO}_{2}$ Inhibition of Terrestrial Isoprene Emission Significantly Affects Future Ozone Projections," Atmospheric Chemistry and Physics, Vol. 9, No. 8, 2009, pp. 2793-2803. doi:10.5194/acp-9-2793-2009

[11] M. T. Benjamin and A. M. Winer, "Estimating the Ozone-Formating Potential of Urban Trees and Shrubs," Atmospheric Environment, Vol. 32, No. 1, 1998, pp. 5368. doi:10.1016/S1352-2310(97)00176-3

[12] H. Taha, "Modeling Impacts of Increased Urban Vegetation on Ozone Air Quality in the South Coast Air Basin," Atmospheric Environment, Vol. 30, No. 20, 1996, pp. 3423-3430. doi:10.1016/1352-2310(96)00035-0

[13] P. Venkatarchi and P. K. Hopke, "Development and Evaluation of a Particle-Bound Reactive Oxygen Species Generator," Journal of Aerosol Science, Vol. 39, No. 2, 2008, pp. 168-174. doi:10.1016/j.jaerosci.2007.11.003

[14] K. Apel and H. Hirt, "Reactive Oxygen Species: Metabolism, Oxidative Stress, and Signal Transduction," Annual Review of Plant Biology, Vol. 55, 2004, pp. 373-399. doi:10.1146/annurev.arplant.55.031903.141701

[15] I. J. George and J. P. D. Abbat, "Heterogeneous Oxidation of Atmospheric Aerosol Particles by Gas-Phase Radicals," Nature Chemistry, Vol. 2, 2010, pp. 713-722. doi:10.1038/nchem.806

[16] T. Franze, M. G. Weller, R. Niessner and U. Pöschl, "Protein Nitration by Polluted Air," Environmental Science Technology, Vol. 39, No. 6, 2005, pp. 1673-1678. doi:10.1021/es0488737

[17] J. Fröhlich-Nowoisky, D. A. Pickersgill, V. R. Despres and U. Pöschl, "High Diversity of Fungi in Air Particulate Matter," Proceedings of the National Academy of Science of the United States of America, Vol. 106, No. 31, 2009, pp. 12814-12819. doi:10.1073/pnas.0811003106

[18] H. Sukopp and R. Wittig, "Stadtökologie“, Gustav Fischer Press, Stuttgart, 1998.

[19] S. Henninger, "A Mobile Measuring Methodology to Determine near Surface Carbon Dioxide within Urban Areas," Air Quality-Models and Applications, 2011, pp. 173-194.

[20] N. J. Brüggemann and J. P. Schnitzler, "Comparison of Isoprene Emission, Intercellular Isoprene Concentration and Photosynthetic Performance in Water-Limited Oak (Quercus pubescence Willd. and Quercus robur L.) Samplings," Plant Biology, Vol. 4, 2008, pp. 456-463.

[21] A. Strassburger, “Analyse Atmosphärischer Spurengase zur Bestimmung des Lufthygienischen Erholungswertes Eines Urbanen Parks," Ph.D. Thesis, University of Duisburg-Essen, 2004.

[22] A. Borbon, H. Fontaione, M. Veillerot, N. Locoge, J. C. Galloo and R. Guillermo, "An Investigation into the Traffic Related Fraction of Isoprene at an Urban Location," Atmospheric Environment, Vol. 35, 2001, pp. 3749-3760. 